\title{
A ROUTINE METHOD FOR TESTING THE SULPHONAMIDE SENSITIVITY OF ORGANISMS CAUSING URINARY INFECTIONS
}

\author{
BY \\ PAMELA JEWELL and G. E. G. PEARMAIN \\ From the Department of Bacteriology, St. George's Hospital Medical School \\ (University of London), S.W.1
}

(RECEIVED FOR PUBLICATION MARCH 13, 1954)

Several methods are available for testing the sensitivity of organisms to the sulphonamide drugs (Harper and Cawston, 1945 ; Evans, 1948 ; Kokko, 1947), but none of them is entirely suitable for clinical use. The main difficu'ty in using a test similar to that for the antibiotics is the presence of sulphonamide-antagonizing substances in routine media. Such substances were first found in peptone (Lockwood, 1938): it was shown that their effect could be counteracted by human blood, heart broth, and serum (Lockwood, 1938 ; Stamp, 1939). Two lines of approach have therefore been followed in developing sulphonamide sensitivity tests, the first using a synthetic medium free from antagonizer (Kokko, 1947) and the second aiming at their removal from ordinary nutrient media (Harper and Cawston, 1945). Elaborate synthetic media have many disadvantages, and organisms may appear more sensitive than in the body. The removal of antagonizer from ordinary routine media by lysed horse cells, as described by Harper and Cawston (1945) and used by Evans (1948), necessitates careful estimation of the amount required for each batch of peptone ; in most cases a high concentration of blood is needed and in this way false results may be obtained.

The present work is an attempt to find a simple technique which will give reliable results, and approaches the problem from a somewhat different angle. An attempt is made to find a simple nutrient medium, the ingredients of which can be shown to be initially free from sulphonamide antagonizers. The experimental work is concerned first with the preparation of a suitable medium and standardization of the technical details of the test, and secondly with an attempt to correlate laboratory and clinical findings in urinary infections, for which sulphonamides are still frequently used.

\section{Experimental}

Determination of Sulphonamide-antagonizer Content and Choice of Medium.-The test organism was a strain of Escherichia coli, sensitive to $0.4 \mathrm{mg} . \%$ of sulphathiazole as estimated by the tube method using absorbed broth (Harper and Cawston, 1945). A synthetic agar medium was prepared containing the sulphonamides in a final concentration of $1 \mathrm{mg} . \%$. The sulphonamides used were sulphathiazole sulphadiazine, sulphamerazine (the components a⿺廴⿻肀二丿 "sulphatriad"), and sulphamezathine. The surface of each plate was diffusely inoculated with the test organism. Heatley cups were placed on the surface and each received 5 drops, from a standard dropper, of a $10 \%$ solution of different commercial brands of peptone : the plates were incubated at $37^{\circ} \mathrm{C}$. Because of the high concentration of sulphonamide, growth did not occur except in the vicinity of those cups which contained sulphonamide antagonizer (Figs. 1a and $1 \mathrm{~b})$. The area of growth around each cup was a measure of the amount of antagonizer present. Woods (1940) showed that $p$-aminobenzoic acid (P.A.B.) had the same effect as the antagonistic substances in peptones, and we therefore measured the antagonizer content in terms of "P.A.B. equivalents" by performing control experiments with varying concentrations of P.A.B. (Table I). It is interesting to 0 note that, whereas with sulphathiazole, sulphadiazine, and sulphamerazine the zones of growth were similar in size, with sulphamezathine the zones were larger. This was probably due to the lower specific activity $N$ of sulphamezathine. With all four drugs, however, Evans peptone had the lowest antagonizer content; $N$ eight batches were tested with consistent results. Lab- స్ట lemco, tested in the same way, showed little or no antagonizer activity with sulphathiazole and sulphadiazine, although there was a definite inhibitory effect against sulphamerazine and sulphamezathine $\stackrel{\mathbb{S}^{\circ}}{\rightarrow}$ (Table I).

In view of these findings a base medium was chosen, $\frac{T}{T}$ containing minimal amounts of antagonizer, and con- $\frac{O}{\mathbb{D}}$ sisted of $0.5 \%$ Evans peptone, $0.3 \%$ Lab-lemco, $1.5 \% \stackrel{\mathbb{P}}{\stackrel{D}{P}}$ 


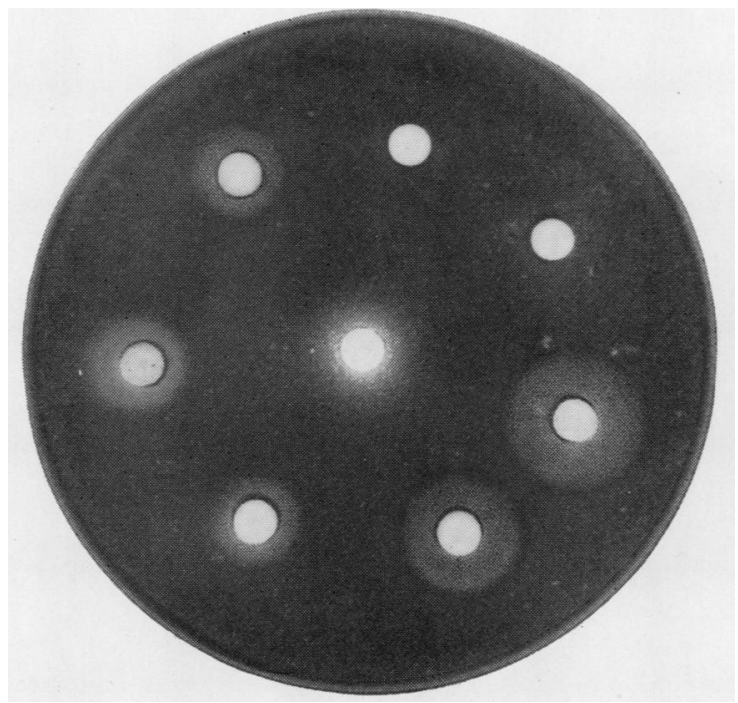

FIG. 1a.-The petri dish contained a synthetic agar medium with 1 ing. \% sulphadiazine. Different brands of peptones were placed in the Heatley cups round the periphery. Haloes of bacterial growth surround all but two, which contained Evans and Oxoid peptones respectively, and are due to diffusion of antagonizer. The halo round the central cup, which contained Lab-lemco, is not produced by bacterial growth but by diffusion of pigments.

TABLE I

CONTENT OF SULPHONAMIDE ANTAGONIZER IN VARIOUS COMMERCIAL PRODUCTS

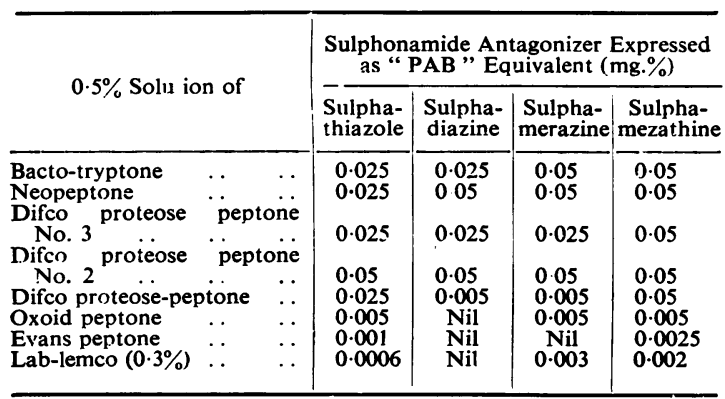

agar (N.Z.), and $0.5 \%$ sodium chloride. When sensitive strains of $E$. coli were tested on this medium by the usual disc method of antibiotic testing appreciable zones of inhibition were obtained, but the zones, on closer scrutiny, contained numerous minute colonies. These were thought to be due to the presence of the traces of antagonizer in the medium, and laked horse blood was added in varying concentration to overcome this effect. It was found that as little as $0.25 \%$ blood in the base medium was sufficient to clear the zones of the minute colonies. The medium finally chosen for the investigation, therefore, had the following composition :

$\begin{array}{llllr}\text { Evans peptone } & \ldots & \ldots & \ldots & 5.0 \mathrm{~g} . \\ \text { Lab-lemco } & . & \ldots & \ldots & 3.0 \mathrm{~g} . \\ \begin{array}{l}\text { Agar powder }(\mathrm{N} . \mathrm{Z} .) \\ \text { Distilled water }\end{array} & \ldots & \ldots & \ldots & 15.0 \mathrm{~g} . \\ & & \ldots & \ldots & 1 \text { litre }\end{array}$

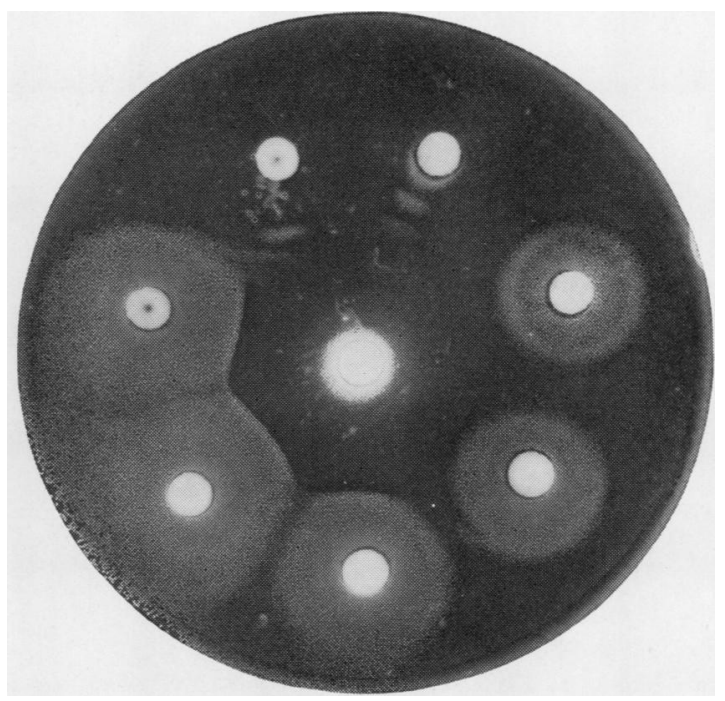

FIG. 1b.-The plate was prepared in a similar way to that in Fig. 1a except that the medium contained $1 \mathrm{mg} . \%$ sulphamezathine insteas of sulphadiazine. The haloes of bacterial growth are generally larger; the effects round Evans and Oxoid peptones remain slight. There is a small halo round the cup containing Lab-lemco.

(With the omission of $\mathrm{NaCl}$ whole horse blood could be added directly to the medium with spontaneous laking.) The ingredients were dissolved in the distilled water, clarified by filtration through paper pulp after adjusting to $p \mathrm{H} 7.2-7.4$ and sterilized by autoclaving for 20 minutes at $15 \mathrm{lb}$. pressure per sq. in. The medium was bottled in $100 \mathrm{ml}$. quantities. Before use it was melted, cooled to $50-56^{\circ} \mathrm{C}$., and $0.5 \%$ of oxalated horse blood added. After thorough mixing plates were poured and stored in the refrigerator for at least 12 hours before use to allow complete neutralization of antagonizer.

Preparation of Sulphonamide-impregnated Blotting Paper Discs.-The organisms were tested against sulphathiazole, sulphadiazine, sulphamerazine, and sulphamezathine. The sodium salts, dissolved in distilled water, were tested in concentrations of 200,300 , and $400 \mathrm{mg}$. per $100 \mathrm{ml}$. After a large number of trials $300 \mathrm{mg}$. per $100 \mathrm{ml}$. was found to give the best correlation with clinical results and this concentration was therefore adopted for the test.

An office punch was used to cut out discs, $6 \mathrm{~mm}$. in diameter, from Ford blotting paper (428 Mill), a different colour being used for each sulphonamide. The discs were placed in $1 \mathrm{oz}$. universal containers and $0.8 \mathrm{ml}$. of sulphonamide solution added for every 100 discs. The containers were then sterilized by autoclaving at $10 \mathrm{lb}$. per sq. in. for 20 minutes. This method was found to give results sufficiently reproducible for routine use.

Inoculum Size.-It is known that the bacteriostatic activity of sulphonamides is related to the inoculum 

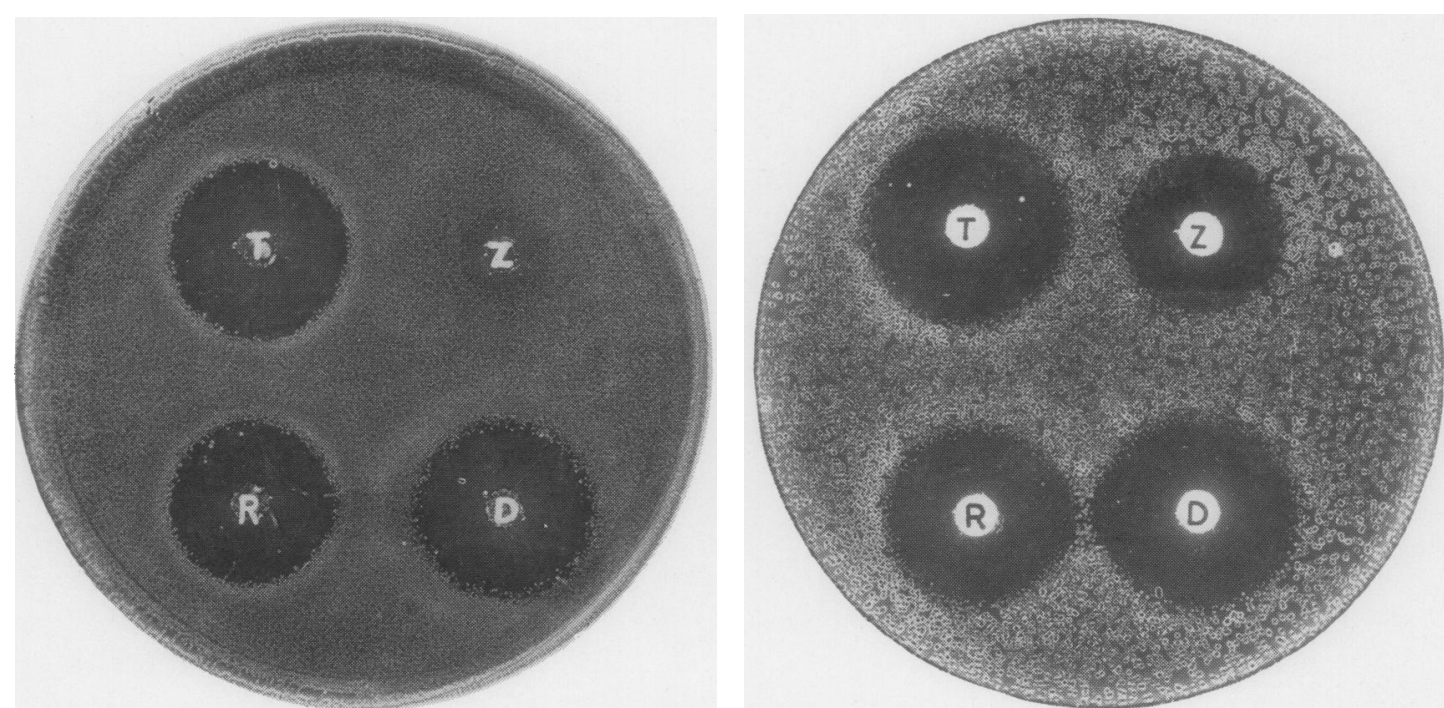

Figs. $2 a$ and $b$. The plates shown were inoculated with the same strain of $E$. coli, and discs containing the four sulphonamides were placed on the surface of each. In Fig. $2 a$ the plate contained base medium plus $05 \%$ laked horse blood: five hours' diffusion was allowed, the discs were removed, the plate inoculated and incubated overnight. Clear zones of inhibition are seen except round the disc containing sulphamezathine. The plate in Fig. $2 b$ was prepared in the same way, but there was no prediffusion, the discs being applied immediately after inoculation. Under these conditions sulphamezathine has produced a clear zone of inhibition similar to those of the other three drugs.

$$
\mathbf{T}=\text { Sulphathiazole }
$$

$$
\mathrm{D}=\text { Sulphadiazine }
$$

$\mathbf{R}=$ Sulphamerazine

$\mathbf{Z}=$ Sulphamezathine

size (Fleming, 1940 ; Colebrook and Francis, 1941). Like Kokko (1947) and Evans (1948) we found that the most satisfactory results were obtained with inocula which gave just discrete colonies in the uninhibited zone. This was readily obtained by lightly touching a colony with the point of a wire and emulsifying it in about $3 \mathrm{ml}$. of sterile saline.

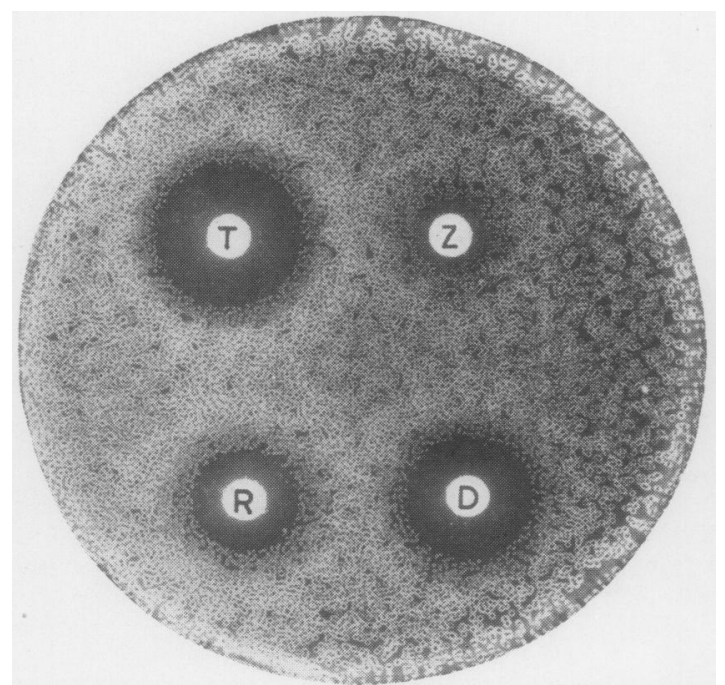

Prediffusion.-Earlier workers (Kokko, 1947 Evans, 1948) found that the best results were obtained if the sulphonamide discs were placed on the surface? of the plate five hours before inoculating. This method of prediffusion was therefore used in the first series of tests. While most organisms showed good zones of inhibition with the components of sulpha-

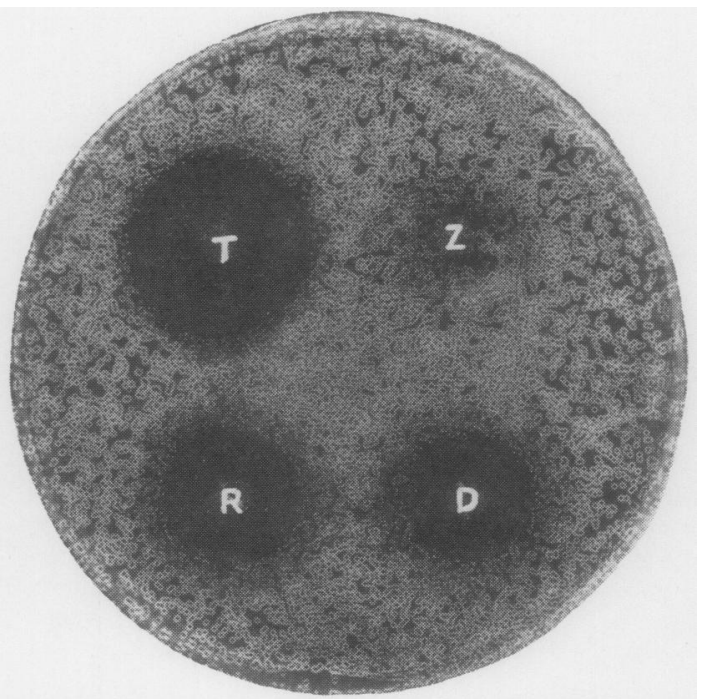

Figs. $3 a$ and $b$. - The medium was absorbed with $6 \%$ laked horse blood, which was removed by heat precipitation and filtration. In Fig. $3 a$ the sulphonamide; were allowed to diffuse into the agar for five hours before the plate was inoculated: in Fig. $3 b$ the sulphonamide discs were placed on the surface of the medium after inoculation. In both cases the zones of inhibition are smaller than in Fig. $2 b$ and the organisms appear "resistant " to sulphamezathine. 
triad, almost half the organisms appeared insensitive or only slightly sensitive to sulphamezathine (Fig. 2a). Some of the patients from whom these organisms were obtained were, however, successfully treated with a course of sulphamezathine, suggesting false results in vitro. At first it was supposed that insufficient blood had been added to remove all the sulphonamide antagonizer, and we therefore retested the effect of sulphamezathine incorporating increasing concentrations of laked horse blood in the base medium. However, as the concentration of blood increased so the organisms apparently became still less sensitive to the drug, suggesting that laked horse blood itself contained a sulphamezathine inhibitor: to prove this the organisms were tested on the base medium alone and considerably larger zones of inhibition were obtained. The time of contact between the sulphamezathine and the blood was then reduced to a minimum by inoculating the plate before the sulphamezathine discs were placed on the surface (that is, without prediffusion), and again good zones of inhibition were obtained (Fig. 2b). For this reason $0.5 \%$ blood was retained in the final medium to eliminate fine growth within the zones of inhibition, but the plates were inoculated without prediffusion of the sulphonamide to minimize the inhibitory effect of the blood on sulphamezathine.

Comparison with a Medium Absorbed with 6\% Laked Horse Blood.-The finding of this apparent inhibitory effect of blood on sulphamezathine led us to compare results on the selected medium with those obtained on a medium containing high concentrations of blood. The method chosen for comparison was that of Evans (1948) which is a well-known blotting paper disc method.

Evans's medium was prepared by incubating sterile nutrient broth (containing oxoid peptone) with $6 \%$ laked horse blood for 24 hours, steaming for half an hour to precipitate the blood, filtering through paper pulp, and solidifying with $1.5 \%$ powdered agar.

A sensitivity test was performed in parallel with one on our medium, the sulphonamide-impregnated blotting paper discs being placed on the surface of the plates after inoculation.

Fig. 3a shows that the zones of inhibition obtained on the absorbed-agar medium were considerably smaller than those on our medium (Fig. 2b): in fact the organism appeared completely resistant to sulphamezathine. Even when the sulphonamides were allowed to diffuse into the absorbed-agar medium for five hours before the plate was inoculated the zones were reduced in size (Fig. 3b). Similar results were obtained when the experiment was repeated with a medium prepared from a different brand of peptone.

From these results we concluded that a high concentration of horse blood can inactivate sulphonamide, particularly sulphamezathine. This effect is still present after the blood is precipitated by boiling and removed by filtration.
FIG. 4.-Graph obtained by determining the inhibitory sensitivity of a number of species of $E$. coli to sulphathiazole and sulphamezathine and plotting against the respective zone diameters obtained by the plate test.

- Strain tested with sulphathiazole $\mathrm{O}-\mathrm{O}$ Strain tested with sulphamezathine

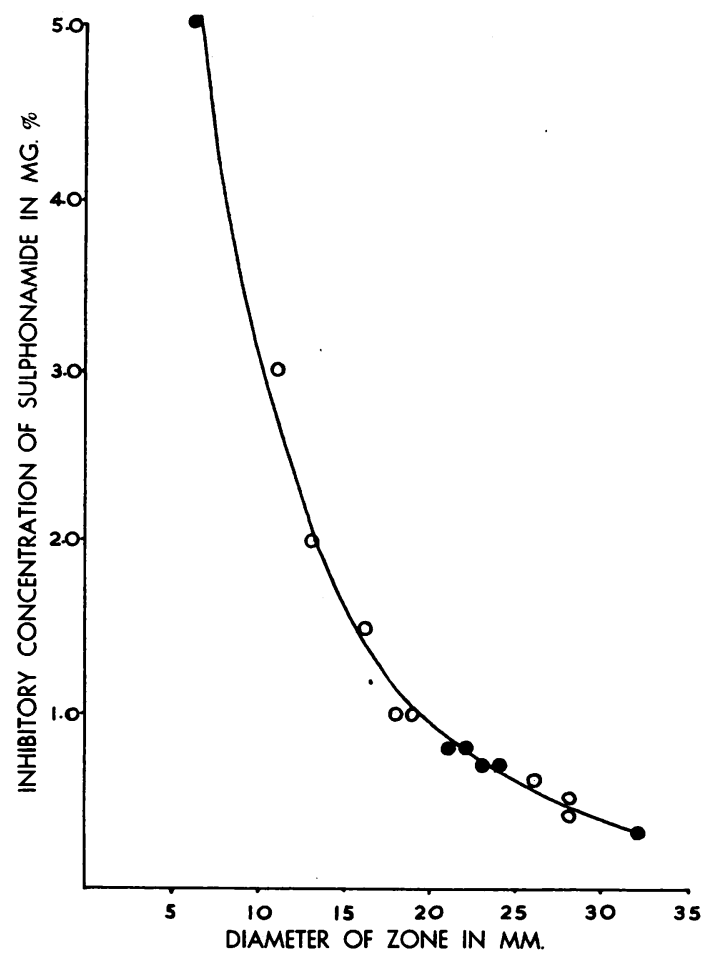

Correlation of Sensitivity of the Organism with Size of the Zone of Inhibition.-The sensitivities of a number of organisms to the four sulphonamides were determined by the tube test (using a broth containing the same ingredients as the base medium, with $0.5 \%$ laked horse blood) and plotted against the diameters of the corresponding zones of inhibition with the plate test. The four curves thus obtained were so similar that for practical purposes they could be considered as one curve (Fig. 4). By measuring the diameter of the zone produced by any one sulphonamide on an unknown organism its approximate inhibitory concentration could be obtained from the curve.

Two out of 39 sensitive organisms showed a fine growth inside the zones of inhibition despite the presence of laked horse blood in the medium. However, their tube sensitivities coincided with those predicted from their zone diameters and it therefore seemed reasonable to treat them in the same way as organisms showing no growth within the inhibition zone. The significance of this observation requires further study. 


\section{Method and Interpretation of the Routine Sensitivity Test}

The medium was prepared as described, and plates were stored for at least 12 hours before use. They were dried for half an hour at $37^{\circ} \mathrm{C}$. and seeded with the standard inoculum by flooding; excess was removed and the plates were placed in the $37^{\circ} \mathrm{C}$. incubator until dry (10-15 minutes). A disc of each sulphonamide was then placed on the surface of the medium and the plates were incubated overnight.

Interpretation.-The method of interpretation was chosen after consideration of reported blood levels. Sulphatriad and sulphamezathine in the doses normally used for urinary infections ( $1 \mathrm{~g}$. six or eight hourly) produce blood levels which are most commonly between 2 and $4 \mathrm{mg}$. per $100 \mathrm{ml}$. (M.R.C. War Memo, 1943 ; Bullowa and Ratish, 1944 ; Volini, Engbring and Schorsch, 1945) although variations among individuals of from 1 to $23 \mathrm{mg}$.\% have been reported (Clark, Murphy, and Flippin, 1943). Organisms with zones of inhibition of more than $15 \mathrm{~mm}$. and therefore sensitive to less than $1.5 \mathrm{mg} \%$ were reported as "sensitive": organisms with zones between 10 and $15 \mathrm{~mm}$. and therefore sensitive to from 1.5 to $3.0 \mathrm{mg} . \%$ as "slightly sensitive," and those with zones of less than $10 \mathrm{~mm}$. as " resistant."

\section{Comparison of Laboratory and Clinical Findings}

In-vitro Findings. - Sixty-three organisms from 50 patients with urinary infections were isolated and tested. Forty-three were E. coli, four A. aerogenes, four $P$. vulgaris, and two atypical coliform bacilli and 10 Strep. faecalis. Nineteen organisms were completely resistant to the four sulphonamides: Table II shows the species distribution.

TABLE II

SULPHONAMIDE SENSITIVITY OF THE DIFFERENT SPECIES OF ORGANISMS

\begin{tabular}{|c|c|c|c|c|c|c|}
\hline \multicolumn{4}{|c|}{ Organism } & \multirow{2}{*}{$\begin{array}{r}\text { No. } \\
40 \\
4 \\
6 \\
3 \\
10\end{array}$} & \multirow{2}{*}{$\begin{array}{c}\text { Sensitive } \\
37 \\
1 \\
4 \\
2 \\
0\end{array}$} & \multirow{2}{*}{$\begin{array}{r}\text { Resistant } \\
3 \\
3 \\
2 \\
1 \\
10\end{array}$} \\
\hline $\begin{array}{l}\text { E. coli . . } \\
\text { A. aerogenes .. } \\
\text { P. vulgaris } \\
\text { Atypical coliform } \\
\text { Strep. faecalis }\end{array}$ & $\begin{array}{l}\cdots \\
\cdots \\
\cdots \\
\cdots\end{array}$ & $\begin{array}{l}\cdots \\
\cdots \\
\cdots \\
\cdots\end{array}$ & $\begin{array}{l}\cdots \\
\cdots \\
\cdots \\
\cdots\end{array}$ & & & \\
\hline \multicolumn{3}{|c|}{ Total } & . & 63 & 44 & 19 \\
\hline
\end{tabular}

With the exception of Strep. faecalis, these results cannot be accepted as the natural sensitivities of the organisms, as all the resistant Gram-negative bacilli were isolated from patients who had been treated with sulphonamide some time previously. Two of these resistant organisms were found to be insensitive to $60 \mathrm{mg}$. \% of sulphathiazole.

Clinical Findings.-Fifty patients with urinary infections were studied: as far as possible they were consecutive cases and treatment was indepen- dent of the laboratory results. A specimen of urine was obtained in each case before treatment and the presence of pus and a heavy growth of organisms were accepted as proof of urinary infection. The patients in this series were given either sulphatriad or sulphamezathine, $1 \mathrm{~g}$. six or eight hourly for five to seven days (in some cases potassium citrate was also given). A second specimen was examined in most cases 24 to 48 hours after the drug had been discontinued: if organisms were present their sensitivity was retested. Sixteen of the 50 patients suffered from acute pyelonephritis, 25 had infections following operations (mainly gynaecological), and nine patients had acute episodes in chronic urinary disease. In 30 patients the infection had been present from one to seven days, in 20 symptoms had been present for over 10 days. From the 50 patients 63 organisms were isolated and incriminated as the cause of infection. In 10 patients a mixed infection of Strep. faecalis and a Gram-negative bacillus was present, and in three cases two species of Gram-negative bacilli were isolated. The correlation between the results in vitro and the clinical findings is shown in Table III. All but one of the 39 patients with

TABLE III

CORRELATION BETWEEN SULPHONAMIDE SENSITIVITY TEST AND CLINICAL RESULTS

\begin{tabular}{|c|c|c|c|c|}
\hline \multirow{2}{*}{ Drug } & \multirow{2}{*}{$\begin{array}{c}\text { Laboratory } \\
\text { Report }\end{array}$} & \multirow{2}{*}{$\begin{array}{c}\text { Total } \\
\text { No. of } \\
\text { Organisms }\end{array}$} & \multicolumn{2}{|c|}{$\begin{array}{l}\text { Correlation with } \\
\text { Clinical Results }\end{array}$} \\
\hline & & & Yes & No \\
\hline Sulphamezathine & $\begin{array}{l}\text { Sensitive } \\
\text { Slightly } \\
\text { sensitive } \\
\text { Resistant }\end{array}$ & $\begin{array}{r}20 \\
5 \\
9\end{array}$ & $\begin{array}{r}20 \\
3 \\
9\end{array}$ & $\begin{array}{l}0 \\
2 \\
0\end{array}$ \\
\hline Sulphatriad & $\begin{array}{l}\text { Sensitive } \\
\text { Slightly } \\
\text { sensitive } \\
\text { Resistant }\end{array}$ & $\begin{array}{r}19 \\
0 \\
10\end{array}$ & $\begin{array}{r}18 \\
0 \\
9\end{array}$ & $\begin{array}{l}1 \\
0 \\
1\end{array}$ \\
\hline Total & 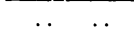 & 63 & 59 & 4 \\
\hline
\end{tabular}

organisms reported as " sensitive" were cured with one course of sulphonamide, even though in 11 of these the infection had been present for more than two weeks: three of these patients had been given a previous course of potassium citrate and two patients chloramphenicol without effect. In one case the organism ( $P$. vulgaris) was present after the course of treatment had been completed, although it was found to be still sensitive. A further course of sulphatriad was successful.

The organisms isolated from five patients treated with sulphamezathine were reported as "slightly sensitive." In two of these the infection was overcome with a single course of the drug. In one of 
the remaining cases a second course of sulphamezathine was needed before the urine was successfully sterilized. In the other two cases the organisms persisted although one patient received 20 and the other $28 \mathrm{~g}$. of sulphamezathine: second courses of sulphamezathine were not given. One of these last two patients had a post-operative urinary infection and was repeatedly catheterized; the other had acute pyelonephritis and the E. coli isolated after treatment was found to be resistant to sulphamezathine. Failure of treatment in these cases was probably due to the narrow margin between the sensitivity of the organisms and the blood levels achieved by the usual dosage of the drug.

Nineteen organisms were reported as " resistant "; 10 of these were Strep. faecalis and the rest various Gram-negative bacilli. In 18 of the cases treatment had no effect on the course of the infection and the organisms isolated after treatment were again found to be completely resistant by the plate test. In the nineteenth case, infected with a "resistant" organism, the one specimen received after treatment was sterile, but the infection recurred soon after: this patient had a suprapubic cystotomy with an indwelling catheter. As the organism was resistant to $30 \mathrm{mg}$. \% sulphathiazole, it is difficult to believe that the drug brought about the temporary cure.

\section{Discussion}

The method described has overcome some of the difficulties encountered in sulphonamide sensitivity testing. The first of these is the presence of sulphonamide antagonizing substances in the ingredients of nutrient media. These can best be dealt with by using media which, by a relatively simple method, can be shown to contain minimal amounts of sulphonamide antagonizer. A very small quantity of laked horse blood is sufficient to remove this trace of antagonizer. It was, however, shown that with some organisms even small quantities of blood are able to inhibit the action of sulphamezathine. This effect can be minimized by placing the sulphonamide-impregnated discs on the surface of the medium after the plate has been seeded with the test organism.

It was also demonstrated that if large concentrations of blood are used to remove antagonizer there is considerable inactivation of all four sulphonamides, shown by a decrease in the size of the zones of inhibition; this occurs even if the blood is removed by heat precipitation and filtration, and whether the sulphonamide is allowed to prediffuse into the medium or not.
Another problem was the occasional occurrence of organisms which constantly gave a fine growth within the zones of inhibition, even on media containing laked horse blood. It was found that their sensitivities by the tube method corresponded with the diameters of the zones and they therefore were reported as "sensitive"; this appears justified by clinical results.

The final difficulty which is inherent in all plate sensitivity tests was that of selecting the concentration of drug for the test plate so that the results in vitro reflect as closely as possible those obtainable in vivo. Although no attempt was made to estimate chemically the amounts of sulphonamide in the agar, a simple test was performed to relate the tube sensitivities of the organisms with their zones of inhibition (Fig. 3). In this way it was shown that, using $300 \mathrm{mg}$. \% of sulphonamide in the disc, the concentrations in the agar at the time the organisms were inhibited agreed well with reported blood levels $(2-4 \mathrm{mg} . \%)$ : any organism sensitive to more than $3 \mathrm{mg}$. \% showed no zone or only slight thinning.

In general, organisms appear either very sensitive to the sulphonamides or completely resistant. Owing to the lesser activity of sulphamezathine, organisms occasionally appear only "slightly sensitive" to this drug and if the usual doses are used for treatment the infection may not be cured. A report "slightly sensitive" to sulphamezathine therefore implies that higher doses should be given or that "sulphatriad" should be used instead.

In the present work we have strictly limited ourselves to organisms obtained from urinary infections. It may be that in other circumstances in vitro results will not reflect the behaviour of the drug in the body and further work is required before the value of the test can be assessed in other types of infection.

\section{Summary}

A simple plate method is described for testing the sensitivities of organisms isolated from urinary tract infections to sulphathiazole, sulphadiazine, sulphamerazine, and sulphamezathine.

The method is based on the choice of a nutrient medium containing minimal traces of sulphonamide antagonizer. The trace of antagonizer is removed by the addition of very low concentrations of laked horse blood, but even the small amounts have inhibitory properties against sulphamezathine, which, however, become marked only if the sulphonamide has been allowed to prediffuse through the medium. 
When large quantities of horse blood are added to remove antagonizer the action of all four sulphonamides is interfered with. Because of this false results are likely to be obtained with some of the methods in current use.

In a series of 50 patients with urinary infections the laboratory tests here described showed excellent agreement with subsequent clinical results.

We are extremely grateful to Dr. S. D. Elek for his continued advice and encouragement throughout the course of this investigation. We also wish to thank the Endowment Fund of St. George's Hospital for a grant towards the expenses of the work.

\section{REFERENCES}

Bullowa, J. G. M., and Ratish, H. D. (1944). J. clin. Invest., 23, 676 Clark, J. K., Murphy, F. D., and Flippin, H. F. (1943). J. Lab. clin. Med., 28, 1828 .

Colebrook, L., and Francis, A. E. (1941). J. Path. Bact., 53, 155.

Evans, R. J. (1948). J. Hyg., Camb., 46, 422.

Fleming, A. (1940). J. Path. Bact., 50, 69.

Harper, G. J., and Cawston, W. C. (1945). Ibid., 57, 59.

Kokko, U. P. (1947). Ann. Med. exp. Biol. Fenn., 25, 79.

Lockwood, J. S. (1938). J. Immunol., 35, 155.

Medical Research Council (1943). War Memo. No. 10

Stamp, T. C. (1939). L.ancet, 2, 10.

Woods, D. D. (1940). Brit. J. exp. Path., 2174.

Volini, I. F.. Engbring, G. M., and Schorsch, H. A. (1945). Arch. intern. Med., 75, 168. 